\title{
Physical Performance Comparison Between Under 15 Elite and Sub-Elite Soccer Players
}

\author{
by \\ Athos Trecroci ${ }^{1}$, Zoran Milanović ${ }^{2}$, Matteo Frontini ${ }^{1}$, F. Marcello Iaia ${ }^{1}$, \\ Giampietro Alberti ${ }^{1}$
}

The aim of this study was to compare the physical performance profile among young soccer players of different competitive levels. Two teams of elite $(n=22)$ and sub-elite $(n=22)$ soccer players at national (highly skilled) and regional (moderately skilled) level were recruited in the study. All participants were tested using a modified Illinois change of direction speed test, a T-drill with and without a ball, a countermovement jump, and a 10-m sprint. The analysis revealed significant differences in favor of elite players in sprint $(d=1.54$, large $)$ and vertical jump $(d=2.03$, very large) outcomes, while no differences were observed in both modified Illinois change of direction speed $(d=0.16$, trivial) and $T$-drill ( $d=0.20$, small $)$ tests between the groups. The ability to change direction and speed with and without a ball was found not to be suitable enough to highlight the difference among youth players with moderate-tohigh level of play. In conclusion, multi-testing approach based on task-related power should include vertical jump and sprint performance to delineate players of a higher level.

Key words: talent selection, change of direction speed, skill assessment, team sports, anaerobic power.

\section{Introduction}

Agility is considered one of the most important determinants of soccer performance. Adult and youth players with a high agility profile are more prone to perform better during high-speed repetitive actions and to make decisions quickly during crucial moments throughout the game (Reilly, 2007; Trecroci et al., 2016; Young et al., 2015). The model of agility consists of two main components representing perceptual and decision-making factors, and change of direction speed. Perceptual and decision-making factors are based on cognitive processes and include specific skills such as visual scanning, anticipation, pattern recognition, and knowledge of situation (Sheppard and Young, 2006; Maszczyk et al., 2018). The change of direction speed (CODS) is based on physical elements including technique, straight sprinting speed, leg muscle qualities (e.g. strength, power and reactive agility) and anthropometry (Sheppard and Young, 2006).

The nature of soccer requires players to have a great ability of accelerating, decelerating, and changing direction in a multidirectional manner and within a few meters. The higher the level of CODS ability, the higher the chance to evade an opponent or to score a goal (Young et al., 2015). Consequently, youth players exhibiting greater abilities than their counterparts would be more likely to dominate during a match. Accordingly, it has been suggested that the CODS may differentiate between athletes of a different competitive level (Scanlan et al., 2011).

From a talent selection viewpoint, it would be important to discriminate which players can be labelled sub-elite, elite or have the potential to achieve a higher level of play based on their physical performance profile. Previous

1 - Department of Biomedical Sciences for Health, Università degli Studi di Milano, Milan, Italy.

2 - Faculty of Sport and Physical Education, University of Nis, Nis, Serbia. 
authors have reported significant differences in vertical jump and sprint performance between youth elite and sub-elite soccer players (Gissis et al., 2006), indicating that power and speed measurements can be used for talent identification processes. On the other hand, the authors highlighted the importance to assess further performance factors (e.g. CODS) to delineate the actual players' ability.

Surprisingly, there is relatively scarce and discordant evidence on selecting talented players throughout the change of direction speed in soccer. Some researchers differentiated between groups of youth elite and sub-elite soccer players using different CODS tests (Gil et al., 2007; Kaplan et al., 2009; Reilly et al., 2000) while others did not (Coelho e Silva et al., 2010; Lago-Peñas et al., 2014). Given the model of the determinants of sports performance (Bangsbo et al., 2006), there is a clear need to measure the athletes' physical performance profile focusing on their ability to perform high-intensity activities (with or without sport-specific skills), to sprint (straight or changing direction) maximally and to achieve high rates of force development in a brief amount of time. In this context, multi-testing approach evaluating physical performance and specific skills in terms of sprinting, jumping and change of direction speed with and without technical elements may provide coaches with much useful information to select those players who are talented (Reilly and Thomas, 1977).

Therefore, the aim of the present study was to compare the physical performance profile between U-15 elite and sub-elite soccer players. We wanted to examine in detail potential differences in the change of direction ability (with and without a ball), short-distance sprint and vertical jump performance.

\section{Methods}

\section{Participants}

Forty-four soccer players (22 elite and 22 sub-elite) from two youth Italian soccer teams were recruited and tested during a week's inseason training period. At the time of the study, elite players were part of a team ranked $9^{\text {th }}$ out of 14 teams that played in the national championship, whereas sub-elite players were part of a team ranked $1^{\text {st }}$ out of 14 teams that played in the regional championship. The soccer teams were classified elite and sub-elite in reference to the definition used by Lorenz et al. (2013) who considered elite athletes as those who played at higher level than peers within a sport (i.e. national vs regional). All participants and their parents were informed about the purpose as well as experimental risks and benefits of the research. Parents or legal guardians provided written informed consent before the investigation. The study was approved by the Ethics Committee of the University of Milan, in accordance with the Declaration of Helsinki as revised in 2013.

\section{Design and Procedures}

To ensure an appropriate execution of the experimental tests, two familiarization trials were conducted in two separate days during the week prior to testing. After 2 days from the last trial, participants completed three testing sessions separated by 72 hours. Before each session, participants were asked to refrain from strenuous physical activities within 48 hours prior to testing. They were also required to wear the same clothing and footwear. In the first session, anthropometric characteristics including body height and mass were recorded and the yo-yo intermittent recovery test level 1 (Yo-Yo IRT liv 1) was carried out to determine the fitness status of each subject (Table 1). In the second and third sessions, participants were instructed to randomly complete all experimental tests for reliability purposes: the $10 \mathrm{~m}$ sprint, countermovement jump (CMJ), modified Illinois agility test (MICODT) and T-drill with a ball. Elite players completed all of the tests on an artificial turf field, at the same time of day (i.e. 3-5 p.m.) as well as sub-elite players (6-8 p.m.), by a random selection. Participants were asked to perform three successful bouts and the average was taken into consideration for further analysis. A recovery period of $10 \mathrm{~min}$ was given between each test to avoid fatigue-induced effects. An electronic timing gates system (Microgate, Bolzano, Italia) was used to obtain each performance time (e.g. 10-m sprint, MICODT and T-drill with a ball). Timing gates were set at $0.7 \mathrm{~m}$ above the ground and placed $0.5 \mathrm{~m}$ back from the starting line.

\section{Countermovement jump measurement}

Jumping performance was assessed by a specific application named My jump (developed for smartphones and tablets) designed for analyzing vertical jumps. This application allows 
users to select two specific frames at the start of the take-off phase (first frame in which feet take off the ground) and at the end of the landing phase (first frame in which one or both feet reach the ground) during a jump. After the selection process, My jump calculates instantly the time (milliseconds) between the two frames and subsequently its corresponding jumping height (centimeters) with a formula proposed by Bosco et al. (1983). Recently, Balsalobre-Fernández et al. (2015) managed to validate this application using a $120 \mathrm{~Hz}$ high-speed camera mounted on an iPhone $5 \mathrm{~s}$ (Apple, Cupertino, CA). For convenience, in the present research, the application was installed on a tablet (iPad Air 2, Apple, Cupertino, CA), which included the same features as the iPhone $5 \mathrm{~s}$. To standardize video recording analysis, the tablet was placed vertically on the ground to face with participants' feet at the distance of $1.5 \mathrm{~m}$. After a brief warm up consisting of low-intensity jumps combined with dynamic stretching, participants were asked to perform three trials of countermovement jumps (CMJs) with hands on their hips, interspersed by $2 \mathrm{~min}$ of resting. During the take-off phase, participants were requested not to bend their legs to avoid a potential increase of the flight time, which would affect their actual jump height.

\section{$10 \mathrm{~m}$ sprint}

The $10 \mathrm{~m}$ sprint is a well-known test considered suitable to discriminate the ability of soccer players to accelerate at a short distance, as previously observed within the literature (Tomás et al., 2014). The protocol consisted of three maximal sprint bouts separated by a recovery period of $2 \mathrm{~min}$. Each bout was performed from a standing position with a free departure. Prior to testing, participants performed a 5 min general warm up with dynamic stretching.

\section{T-drill test with a ball}

The T-drill test is based on the same scheme as the T-drill classic test with the inclusion of four balls and a soccer goal. This test was chosen owing to its simplicity in measuring CODS ability combined with technical skills (i.e. kicking). The T-drill test with a ball was previously proposed by Kutlu et al. (2012) who observed an acceptable test-retest reliability and inter-rater reliability scores. Kutlu et al. (2012) also suggested the use of T-drill with a ball for discriminating players presenting different levels of play. Participants were instructed to sprint forward and kick the first ball with their right leg inside a soccer goal at $\sim 10 \mathrm{~m}$ distance. Then, they shuffled to the left side kicking the second ball and shuffled back to the right side kicking the third and the fourth ball by alternating the shooting leg. After that, they ran backwards to the starting position. For each ball kicked inside the goal (score) $0.25 \mathrm{~s}$ was subtracted from the total time required to complete the course. For example, in the event of four scores, a reduction of $1 \mathrm{~s}$ was applied to the total time. A recovery of 2 min was given between the trials.

\section{Modified Illinois change of direction test}

The MICODT is a new version of the widely practiced Illinois CODS test validated by Hachana et al. (2014). The pattern movements of the test involved sprints, changes of direction, turning and slalom runs around seven cones. On command, participants performed a $5 \mathrm{~m}$ sprint, turned around the cone and returned back diagonally to the starting line. Then, they swerved in and out of three cones completing a subsequent diagonal and a straight 5-m sprint to finish the course. Participants were instructed no to cut over the cones but move around without touching or hitting them. In of the event that participants failed to follow instructions, the trial was invalidated and after sufficient recovery (i.e. 2 $\min$ ), they were asked to repeat the course.

\section{Statistical analysis}

The Kolmogorov-Smirnov test was conducted to verify if all data met the normality test assumption. Test-retest reliability was assessed for all tests using a one-way Intra-class correlation coefficient (ICC) based on average measurements (ICC $1, \mathrm{k})$. Independent $\mathrm{t}$ tests were used with competitive standard (elite vs. subelite) as the between group factor to evaluate potential differences in age, anthropometry and fitness status as well as in acceleration, vertical jump and change of direction speed. The effect size (standardized differences in means, $d$ ) was calculated to assess the meaningfulness of the difference in the performance scores. According to Hopkins (2010), it was classified as trivial $(d<0.2)$, small $(0.2<d<0.6)$, moderate $(0.6<d<1.2)$, large $(1.2<d<2.0)$, and very large $(2.0<d<4.0)$. All analyses were performed using the IBM SPSS Statistics (v. 21, New York, U.S.A.) and data are shown as mean \pm SD. An alpha value of $p<0.05$ 
was set as the criterion level of significance.

\section{Results}

Both elite and sub-elite groups of players presented non-significant differences $(p>0.05)$ in mean age, body height and mass, however, elite players were superior in the Yo-Yo IRT liv 1 outcome ( $p=0.04, d=0.8$ ) (Table 1$)$. A high value of test-retest reliability was observed in all experimental tests $(\mathrm{CMJ}, \mathrm{ICC}=0.952 ; 10 \mathrm{~m}$ sprint, ICC $=0.937$; T-drill with a ball, ICC $=0.914$ );
MICODT, ICC $=0.902$ ). Additionally a significant difference was found between elite and sub-elite players for 10-m sprint $\left(\mathrm{t}_{(42)}=-4.507, p<0.0001, d=\right.$ 1.54) and countermovement jump performance $\left(\mathrm{t}_{(42)}=6.731, p<0.0001, d=2.03\right)$, respectively (Figures 1 and 2). On the other hand, no differences were observed in the MICODT $\left(\mathrm{t}_{(42)}=\right.$ $0.509, p=0.61, d=0.16$ ) and T-drill performance $\left(\mathrm{t}_{(42)}=-0.691, p=0.49, d=0.20\right)$ between under 15 elite and sub-elite soccer players (Figure 3 ).

Table 1

Characteristics of elite $(\mathrm{N}=22)$ and sub-elite $(\mathrm{N}=22)$ soccer players

\begin{tabular}{ccccccc}
\hline Level & $\begin{array}{c}\text { Age } \\
(\text { years })\end{array}$ & $\begin{array}{c}\text { Body height } \\
(\mathrm{m})\end{array}$ & $\begin{array}{c}\text { Body mass } \\
(\mathrm{kg})\end{array}$ & $\begin{array}{c}\text { Yo-Yo IRT liv 1 } \\
(\mathrm{m})\end{array}$ & $\begin{array}{c}\text { Training routine } \\
\left(\mathrm{n}^{\circ} \text { of sessions }\right. \\
\text { per week })\end{array}$ \\
\hline Elite & $14.58 \pm 0.50$ & $1.70 \pm 0.06$ & $57.06 \pm 5.87$ & $1604.71 \pm 356.33^{*}$ & 4 \\
Sub-Elite & $14.23 \pm 0.43$ & $1.68 \pm 0.09$ & $55.20 \pm 7.78$ & $1338.82 \pm 366.36$ & 3 \\
\hline & $* p<0.05$, significant differences between elite and sub-elite soccer players.
\end{tabular}

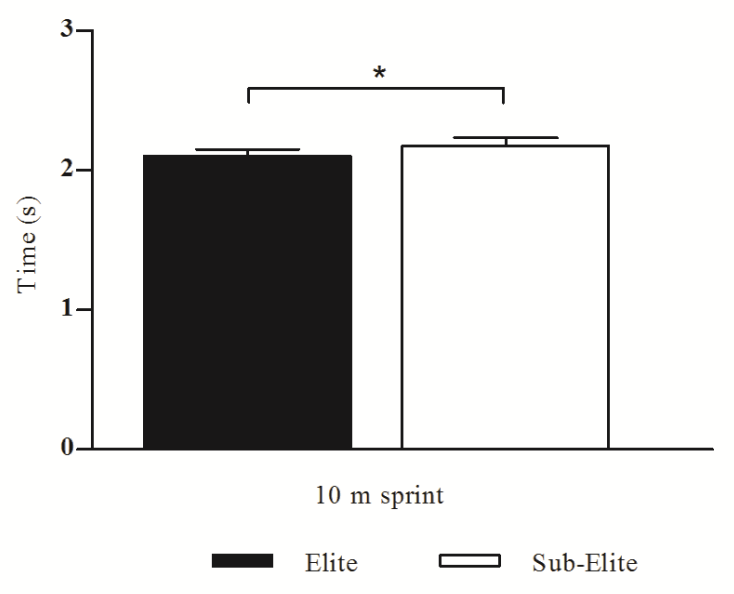

Figure 1

$10 \mathrm{~m}$ sprint time of both elite and sub-elite groups of players (mean $\pm S D$ ).

${ }^{*}$ Indicates significant $(p<0.0001)$ difference between the two groups of players (elite vs sub-elite) 


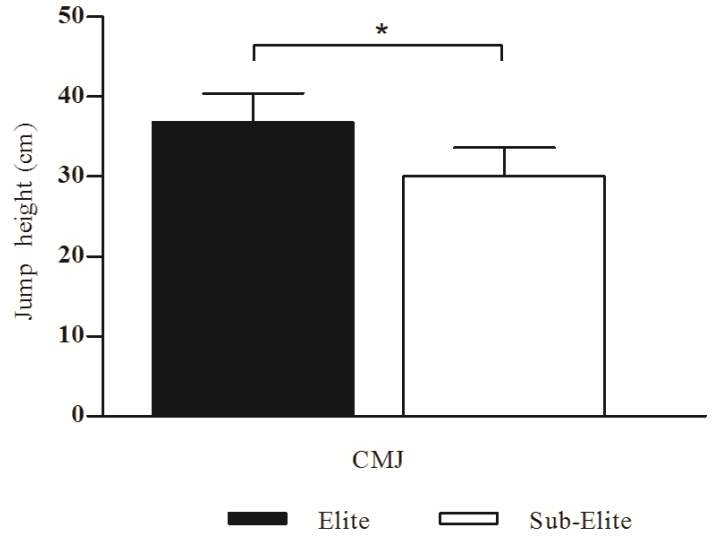

Figure 2

Countermovement jump (CMJ) height of both elite and sub-elite groups of players (mean $\pm S D$ ).

*Indicates significant $(p<0.0001)$ difference between the two groups of players (elite vs sub-elite).

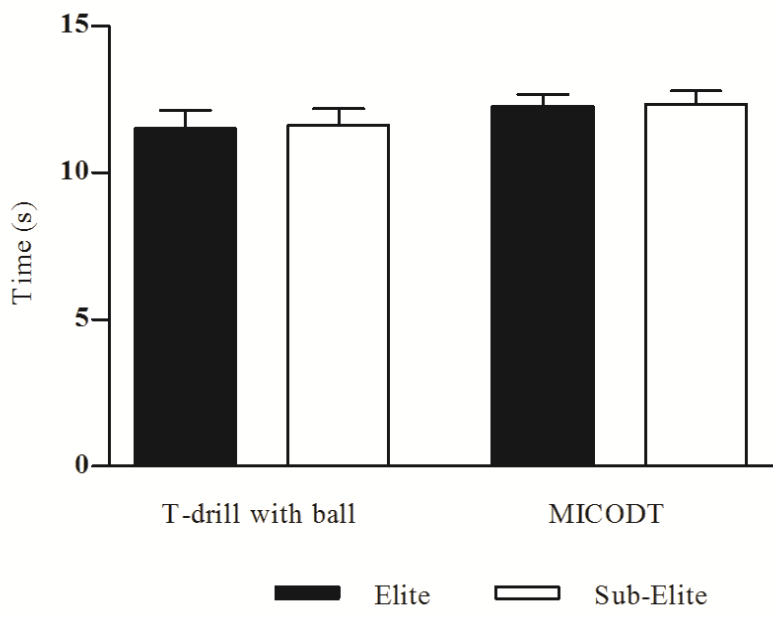

Figure 3

Running times of the change of direction speed tests of both elite and sub-elite groups of players (mean $\pm S D$ ).

Note: MICODT, modified Illinois change of direction test. 


\section{Discussion}

The main findings of the present study were that CODS ability, assessed with and without a ball, was not sensitive enough to determine differences between U-15 elite and subelite soccer players. Conversely, physical capacities in terms of vertical jumping and sprinting performance were found to be suitable in detecting significant differences with respect to the level of play.

The ability to rapidly decelerate, change body direction and accelerate is an important prerequisite throughout the match, increasing the chance of players to win one-on-one duels or perform effective defending maneuvers (Reilly, 2007; Trecroci et al., 2016; Young et al., 2015). Thus, both youth and adult players of a high competitive level should present a better CODS profile than their lower level counterparts. However, the latter assumption is in contrast with the present results. A possible explanation can be related to the fact that, during a match, players' ability to change direction depends not only on the physical capacity, but also on perceptual and decision-making factors, which are known to refer as to reaction skills (Sheppard and Young, 2006). According to Lockie et al. (2014), elite performers differ from their sub-elite peers in those decisionmaking factors affecting the response to unpredictable stimuli (i.e. unplanned condition). From a speculative point of view, it may be likely that the planned nature of both MICODT and Tdrill tests used in this study might have masked potential difference in reaction skills between elite and sub-elite soccer players. Unfortunately, the assessment of reaction skills was beyond the aim of our study, thus the latter speculation should be interpreted with caution. However, our findings seem to be in line with those of other studies, which investigated the CODS ability through various tests and over many sports. Gabbet et al. (2008) observed no significant differences in the Lrun test among rugby players belonging to different leagues. Similarly, other authors failed to find any significant changes in the Y-shaped test performance among groups of basketball players and female hockey players with different levels of play (Lockie et al., 2014; Morland et al., 2013). Conversely, some authors succeeded to observe changes in the CODS outcomes in soccer (Sierer et al., 2008) and netball players (Farrow et al., 2005).
Likewise, previous soccer research provided conflicting conclusions compared to our main findings (Coelho e Silva et al., 2010; Gil et al., 2007; Kaplan et al., 2009; Reilly et al., 2000). In their multidisciplinary approach, Reilly et al. (2000) found that youth elite players not only showed a greater performance in sprinting and vertical jumping, but also performed significantly better in the CODS tests with (i.e. slalom dribble test) and without a ball (i.e. 40-m sprint with cones) compared to their sub-elite counterparts. This contrasting finding can be partially attributed to the nature of CODS tests used by Reilly et al. (2000) in which the same type of directional changes was applied. In fact, during the 40-m sprint with cones, athletes performed subsequent diagonal runs interspersed by cutting movements. Such tests based on fixed changes of direction (e.g. zig-zag circuit courses and shuttle tasks) are known to depend predominantly on athletes' ability to sprint linearly (Lockie et al., 2013). Thus, it may suggest that any potential difference among players would be highlighted by CODS tests focusing on skills (e.g. technique, balance and coordination) rather than muscle qualities (e.g. power and strength levels) (Brughelli et al., 2008).

Muscle power and speed are central physiological characteristics of soccer players, which allow them to execute explosive actions such as sprinting, jumping and kicking throughout a match. According to the present findings, elite players presented greater ability to accelerate over $10 \mathrm{~m}$ and to jump higher than their sub-elite counterparts, showing a marked physical superiority. In literature, other studies have reported similar results (Gil et al., 2007; Gissis et al., 2006). Gissis et al. (2006) observed that under 17 elite soccer players could be distinguished from their sub-elite peers considering their strength level (e.g. maximal isometric strength), power performance (e.g. vertical jump ability) and speed characteristics (acceleration up to $10 \mathrm{~m}$ ). Likewise, in the study of Gil et al. (2007), high-level 14- to 17-year-old players showed superior performance in the countermovement jump and $30 \mathrm{~m}$ sprint compared to age-matched players of a lower competitive level. The reason behind this performance discrepancy may be linked to the specific criteria of talent selection processes, 
which are mostly orientated towards selecting taller, heavier and stronger players (Malina et al., 2004), thus focusing on early maturing subjects.

The main limitation of the current study is the lack of biological maturity status data, which would provide additional information to compare the physical performance differences in terms of acceleration, vertical jump and change of direction speed existing between elite and sub-elite youth soccer players.

\section{Conclusion}

The assessment of physical performance in terms of $10 \mathrm{~m}$ sprint and countermovement

\section{Acknowledgements}

We would like to thank Andrea Millefanti (MSc) for the assistance in collecting data, and A.S.D. Varesina CV and A.S. Varese 1910 soccer teams for cooperation and support.

\section{References}

Balsalobre-Fernández C, Glaister M, Lockey RA. The validity and reliability of an iPhone app for measuring vertical jump performance. J Sports Sci, 2015; 33(15): 1574-1579

Bangsbo J, Mohr M, Poulsen A, Perez-Gomez J, Krustrup P. Training and testing the elite athlete. J Exerc Sci Fit, 2006; 4(1): 1-14

Bosco C, Luhtanen P, Komi PV. A simple method for measurement of mechanical power in jumping. Eur J of Appl Physiol Occup Physiol, 1983; 50(2): 273-282

Brughelli M, Cronin J, Levin G, Chaouachi A. Understanding change of direction ability in sport. Sports Medicine, 2008; 38(12): 1045-1063

Coelho e Silva MJ, Figueiredo AJ, Simões F, Seabra A, Natal A, Vaeyens R, Malina RM. Discrimination of U14 Soccer Players by Level and Position. Int J Sports Med, 2010; 31(11): 790-796

Farrow D, Young W, Bruce L. The development of a test of reactive agility for netball: a new methodology. $J$ Sci Med Sport, 2005; 8(1): 52-60

Gabbett TJ, Kelly JN, Sheppard JM. Speed, Change of Direction Speed, and Reactive Agility of Rugby League Players. J Strength Cond Res, 2008; 22(1): 174-181

Gil S, Ruiz F, Irazusta A. Selection of young soccer players in terms of anthropometric and physiological factors. J Sports Med Phys Fitness, 2007; 47(1): 25-32

Gissis I, Papadopoulos C, Kalapotharakos V, Sotiropoulos A, Komsis G, Manolopoulos E. Strength and speed characteristics of elite, subelite, and recreational young soccer players. Res Sports Med, 2006; 14(3): 205-214

Hachana Y, Chaabène H, Ben Rajeb G, Khlifa R, Aouadi R, Chamari K, Gabbett TJ. Validity and reliability of new agility test among elite and subelite under 14-soccer players. PLoS One, 2014; 9(4): e95773

Hopkins WG, Schabort EJ, Hawley JA. Reliability of power in physical performance tests. Sports Med, 2001; 31(3): 211-234

Kaplan T, Erkmen N, Taskin H. The evaluation of the running speed and agility performance in professional and amateur soccer players. J Strength Cond Res, 2009; 23(3): 774-778

Kutlu M, Yapıcı H, Yoncalık O, Çelik S. Comparison of a new test for agility and skill in soccer with other agility tests. J Hum Kinet, 2012; 33: 143-150

(C) Editorial Committee of Journal of Human Kinetics compare the competitive level between U-15 elite and sub-elite soccer players. Given that, the recommending coaches to include acceleration and vertical jump assessments rather than CODS tests to discriminate physical performance of youth soccer players. Further studies should be maturation (e.g. through non-invasive procedures) of each player to control for possible confounding results. 
Lago-Peñas C, Rey E, Casáis L, Gómez-López M. Relationship between performance characteristics and the selection process in youth soccer players. J Hum Kinet, 2014; 40: 189-199

Lockie RG, Jeffriess MD, McGann TS, Callaghan SJ, Schultz AB. Planned and reactive agility performance in semi-professional and amateur basketball players. Int J of Sports Physiol Perform, 2014; 9(5): 766-771

Lockie RG, Schultz AB, Callaghan SJ, Jeffriess MD, Berry SP. Reliability and validity of a new test of changeof-direction speed for field-based sports: the change-of-direction and acceleration test (CODAT). $J$ Sports Sci Med, 2013; 12(1): 88-96

Malina RM, Eisenmann JC, Cumming SP, Ribeiro B, Aroso J. Maturity-associated variation in the growth and functional capacities of youth football (soccer) players 13-15 years. Eur J Appl Physiol, 2004; 91(5-6), $555-562$

Maszczyk A, Gołaś A, Pietraszewski P, Kowalczyk M, Cięszczyk P, Kochanowicz A, Smółka W, Zając A. Neurofeedback for the enhancement of dynamic balance of judokas. Biol. Sport, 2018; 35: 99-102

Morland B, Bottoms L, Sinclair J, Bourne N. Can change of direction speed and reactive agility differentiate female hockey players? Int J Perform Anal Sport, 2013; 13(2): 510-521

Reilly T. The science of training - soccer: a scientific approach to developing strength, speed and endurance. New York: Routledge; 2007

Reilly T, Thomas V. Applications of multivariate analysis to the fitness assessment of soccer players [proceedings]. Br J Sports Med, 1977; 11(4), 183-184

Reilly T, Williams AM, Franks A. A multidisciplinary approach to talent identification in soccer. J Sports Sci, 2000; 18(9): 695-702

Scanlan A, Dascombe B, Reaburn P. A comparison of the activity demands of elite and sub-elite Australian men's basketball competition. J Sports Sci, 2011; 29(11): 1153-1160

Sheppard JM, Young WB. Agility literature review: classifications, training and testing. J Sports Sci, 2006; 24(9): 919-32

Sierer SP, Battaglini CL, Mihalik JP, Shields EW, Tomasini NT. The national football league combine: performance differences between drafted and nondrafted players entering the 2004 and 2005 drafts. J Strength Cond Res, 2008; 22(1): 6-12

Tomáš M, František Z, Lucia M, Jaroslav T. Profile, correlation and structure of speed in youth elite soccer players. J Hum Kinet, 2014; 40: 149-159

Trecroci A, Milanović Z, Rossi A, Broggi M, Formenti D, Alberti G. Agility profile in sub-elite under-11 soccer players: is SAQ training adequate to improve sprint, change of direction speed and reactive agility performance? Res Sports Med, 2016; 24(4): 331-340

Young WB, Dawson B, Henry GJ. Agility and change-of-direction speed are independent skills: implications for training for agility in invasion sports. Int J Sports Sci Coach, 2015; 10(1): 159-169

\title{
Corresponding author:
}

\author{
Athos Trecroci, PhD \\ Department of Biomedical Sciences for Health \\ Via Kramer 4/A \\ 20129 Milano \\ tel: +39 3474128375 \\ E-mail: athos.trecroci@unimi.it
}

